Casos Clínicos

Arch. Esp. Urol. 2009; 62 (8): 671-673

\title{
ADENOCARCINOMA PRIMARIO DE VESÍCULAS SEMINALES
}

Ana Martínez-Peñuela, María Rosario Mercado, Javier Aldave y José Maria Martínez-Penuela.

Servicio de Anatomía Patológica y Servicio de Urología'. Hospital de Navarra. Pamplona. Navarra. España.

Resumen.- OBJETIVOS: Presentar un caso de adenocarcinoma primario de vesícula seminal.

MÉTODO/RESULTADOS: Varón de 69 años con síntomas de uropatía obstructiva, que presenta al tacto rectal un agrandamiento del área posterior de la próstata y tejidos adyacentes. La biopsia transrectal revela un adenocarcinoma papilar primario de vesículas seminales.

CONCLUSIÓN: El adenocarcinoma primario de vesículas seminales es una neoplasia extremadamente infrecuente, que es de difícil diagnóstico tanto por su morfología inespecífica como por su localización, dado que se puede confundir con otros adenocarcinomas primarios como de la próstata, vejiga o recto.

Palabras clave: Primary adenocarcinoma. Seminal vesicles.

Ana Martínez-Peñuela

Servicio de Anatomía Patológica

Hospital de Navarra

Irunlarrea, 3

31008 Pamplona Navarra (España).

amartmar@cfnavarra.es

Trabajo recibido: 24 de marzo 2009. 
Summary.- OBJECTIVES:To report one case of primary adenocarcinoma of the seminal vesicles.

METHODS/ RESULTS: We report the case of a 69-yearold man with obstructive voiding symptoms. Digital rectal examination reveals a marked enlargement of posterior area of the prostate and surrounding tissues. Transrectal needle biopsy shows a primary adenocarcinoma of the seminal vesicles.

CONCLUSION: Primary adenocarcinoma of the seminal vesicles is an extremely uncommon neoplasm that is often difficult to diagnose as it has inespecific morphology and can be confused with other primary adenocarcinomas from prostate, bladder or colon.

Keywords: Primary adenocarcinoma. Seminal vesicles.

\section{INTRODUCCIÓN}

Los tumores primarios de las vesículas seminales son extremadamente raros y generalmente difíciles de diagnosticar, sobre todo los epiteliales, debido a que se suelen confundir con otros adenocarcinomas primarios, generalmente de origen en próstata, vejiga o recto. Uno de los criterios fundamentales para su diagnóstico es la necesidad de que no haya otro tumor primario en órganos adyacentes, además, a este criterio se unen hoy en día el hecho de que se trate de un adenocarcinoma papilar que recuerde en cierta medida a la mucosa normal de las vesículas, y la obligatoriedad de que el PSA en inmunohistoquímica sea negativo. En la actualidad varios estudios se han dirigido a buscar un anticuerpo específico de vesícula seminal y carcinomas primarios.

Generalmente la mayoría de estos tumores se diagnostican en estadíos avanzados, por lo que su pronóstico es malo.

\section{MATERIAL Y MÉTODOS}

Paciente varón de 69 años con ligeros síntomas de uropatía obstructiva de un año de evolución, y ocasional disuria y dificultad eyaculatoria. El tacto rectal revela una gran masa indurada en área posterior de la próstata y tejidos circundantes. El TAC pone en evidencia una tumoración de unos $9 \mathrm{~cm}$ de diámetro máximo en zona posterior de la próstata, sobre todo afectando a lado derecho con infiltración de ambas vesículas seminales y extensión a tejidos blandos. El PSA en suero es normal $(1,2 \mathrm{ng} / \mathrm{ml})$. Se realizan biopsias transrectales.

El estudio histológico muestra una neoformación epitelial atípica marcadamente infiltrante, que crece en parte formando estructuras papilares con ejes conectivovasculares y en parte formando glándulas irregulares y tamaños variables. Las células son de mediano tamaño, de escaso citoplasma basófilo y núcleos grandes, hipercromáticos, en ocasiones con nucleolo de gran tamaño. Muestran marcada anisocariosis y atipia (Figura 1). La tumoración provoca marcada reacción estromal y un ligero infiltrado inflamatorio linfoplasmocitario. No se observa tejido histológicamente normal. Así, con el diagnóstico de adenocarcinoma papilar de alto grado, se realiza estudio inmunohistoquímico con PSA (Prediluído Ventana) siendo negativo y descartando casi con seguridad que se trate de un primario prostático. Se procede entonces a descartar la presencia de una neoplasia bien vesical o de recto mediante estudios endoscópicos y radiológicos no evidenciándose otras neoplasias. Se amplia el estudio inmunohistoquímico con la sospecha de que se trate de un primario de vesículas seminales observándose intensa inmunorreactividad de las células tumorales frente a Citoqueratina 7 (1:50 Novocastra) y Ca 125 (Prediluído Novocastra) y ligera frente a MUC6 (1:50 Novocastra) (Figura 2). La Citoqueratina 20 (1:25 Novocastra) resulta negativa. Así con la combinación de la morfología papilar de alto grado y el resultado inmunohistoquímico se diagnostica de adenocarcinoma primario de vesículas seminales.

Al paciente se le practica prostatovesiculectomía radical y actualmente está en tratamiento con antiandrógenos.

\section{DISCUSIÓN}

Los tumores primarios de las vesículas seminales son extremadamente raros. El diagnóstico de un adenocarcinoma primario de vesículas seminales requiere la exclusión en primer lugar, de un tumor prostático. Además, aunque son igualmente infrecuentes, se debería descartar la presencia de un adenocarcinoma de origen vesical (1) o incluso de uréter (2) además de recto.

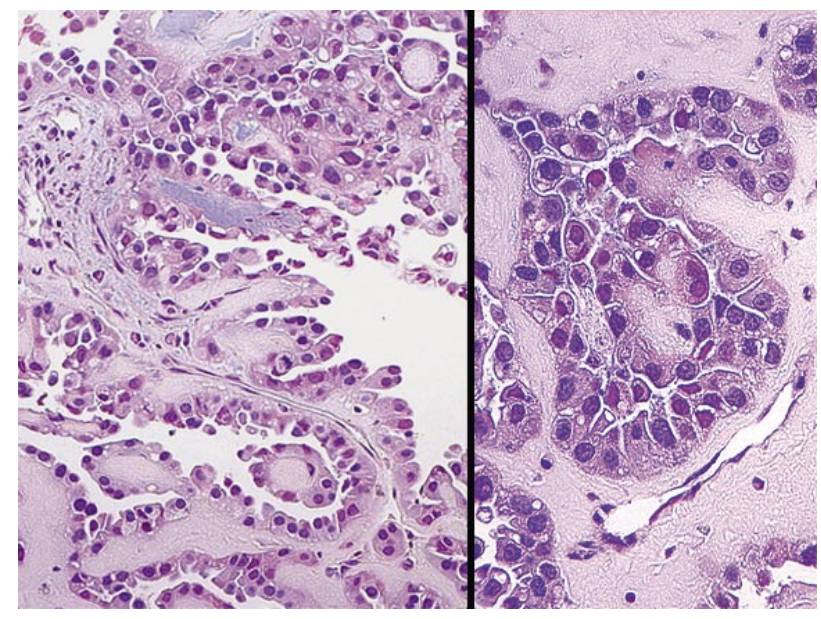

FIGURA 1. El tumor es un adenocarcinoma papilar de alto grado. 
El adenocarcinoma de vesículas seminales es un tumor que se presenta con una edad media de 62 años.

Los principales síntomas y signos son de uropatía obstructiva y con menor frecuencia de hematuria o hematospermia. El antígeno carcinoembrionario puede o no estar elevado. Son tumores generalmente grandes (2-5 $\mathrm{cm}$ ), que frecuentemente invaden los tejidos periprostáticos, próstata, vejiga y/o recto $(3,4)$.

Desde el punto de vista histopatológico son tumores que pueden mostrar patrones mixtos trabecular, papilar y glandular con grados diferentes de diferenciación y por ello es fácil confundirlos con otros adenocarcinomas primarios, generalmente de origen en próstata, vejiga o recto. Son diversos los estudios que han buscado un anticuerpo específico de vesícula seminal normal y tumoral (5-10). Así Ormsby et al. (5) proponen un panel de anticuerpos constituido por Cal25, Citoqueratina (CK)7, CK20 y PSA para el diagnóstico diferencial de tumores de la región de vesículas seminales, incluyendo próstata, vejiga y recto. Por otro lado otros estudios proponen el anticuerpo MUC6 como marcador del conducto eyaculatorio y vesículas seminales normales $(6,7)$. Hasta la fecha no hay evidencia de que alguien haya realizado este anticuerpo sobre tejido tumoral. Nosotros obtuvimos una ligera positividad con el MUC6 lo que hace suponer que podría incluirse este anticuerpo en el panel propuesto por Ormsby et al.

Así el perfil inmunohistoquímico del adenocarcinoma primario de vesícula seminal sería la positividad frente a CK7, Cal 25 y MUC6 y negativo para PSA y CK20.

El tratamiento actual de elección es la resección quirúrgica amplia con márgenes libres. El papel de la radioterapia no está claro todavía aunque se sugiere que podría tener beneficios como tratamiento neoadyuvante. En cuanto al tratamiento hormonal, la escasa ex-

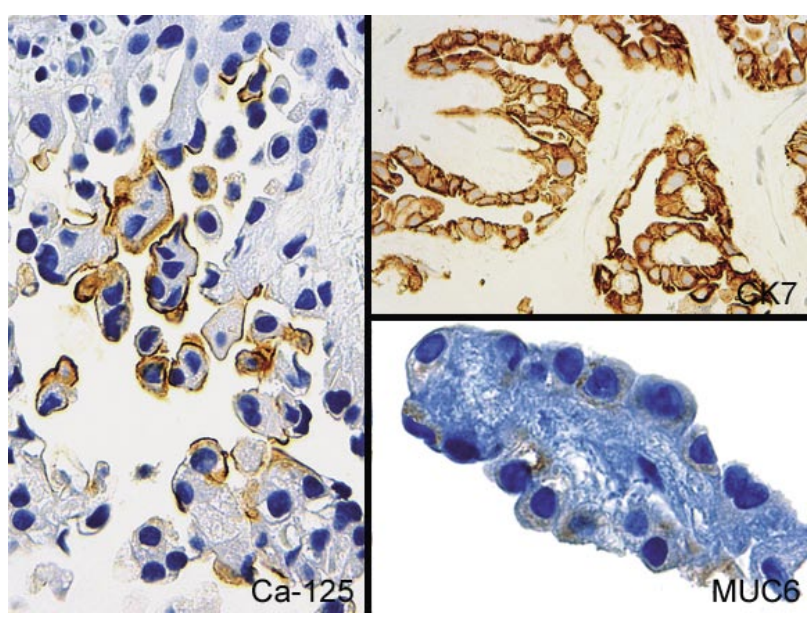

FIGURA 2. Las células tumorales muestran inmunorreactividad frente a Ca-125, Keratina7 y MUC6. periencia que se tiene advierte que podría pronlongar la supervivencia debido a que retrasaríala aparción de recidivas.

El pronóstico de estos tumores en general es pobre observándose en el $95 \%$ de los casos una supervivencia menor de tres años.

\section{CONCLUSIÓN}

Aportamos un nuevo caso excepcional de adenocarcinoma primario de vesículas seminales a la literatura, corroborando los resultados del panel de anticuerpos diagnóstico propuesto con anterioridad y sugiriendo la posibilidad de añadir el MUC6 a dicho panel.

\section{BIBLIOGRAFÍA y LECTURAS RECOMENDADAS (*lectura de interés $y^{* *}$ lectura fundamental)}

1. Soares M J, Neves T, Covita T, Monteiro P, Canhoto $\mathrm{P}$, Nogueira R. et al. Adenocarcinoma vesical. Aportación de un caso. Arch Esp Urol, 2008; 61:828-31

2. Granados E A. Adenocarcinoma primario de uréter. Arch Esp Urol, 2001; 54:464-6.

3. Zhou M, Magi-Galluzzi C. Genitourinary Pathology. Churchill Livingstone. Philadelphia 2007.

4. Eble J N, Sauter G, Epstein J I, Sesterhenn I A. World Health Organization Classification of tumours. Pathology and Genetics of Tumours of the urinary system and male genital organs. IARC Press. Lyon 2004.

*5. Ormsby AH, Haskell R, Jones D, Goldblum JR. Primary Seminal Vesicle Carcinoma: an immunohistochemical analysis of four cases. Mod Pathol, 2000; 13; 46-51.

6. Bartmann AE, Buisine MP, Aubert JP, Niehans GA, Toribara NW, Kim YS et al. The MUC6 secretory mucin gene is expressed in a wide variety of epithelial tissues. J Pathol, 1998; 186: 398-405.

**7. Leroy X, Ballereau C, Villers A, Saint F, Aubert S, Gosselin B et al. MUC6 is a marker of seminal vesicle-ejaculatory duct epithelium and is useful for the differential diagnosis with prostate adenocarcinoma. Am J Surg Pathol, 2003; 27: 519-521.

8. Thiel R, Effert P. Primary adenocarcinoma of the seminal vesicles. J Urol, 2002; 168; 1891-1896.

9. Egevad L, Ehrnstrom R, Hakansson U, Grabe M. Primary seminal vesicle carcinoma detected at transurethral resection of prostate. Urology, 2007; 69: 778.

10. Mohring C, Bach P, Kosciesza S, Goepel M. A primary adenocarcinoma of the seminal vesicles. Case report of a rare malignancy. Urologe A, 2008; 47; 616-9. 